\title{
Ireland at the United Nations: Memories of the Early Years A Small State at the Top Table: Memories of Ireland at the Security Council, 1981-82
}

Christophe Gillissen

\section{(2) OpenEdition Journals}

\section{Édition électronique}

URL : https://journals.openedition.org/etudesirlandaises/3238

DOI : 10.4000/etudesirlandaises.3238

ISSN : 2259-8863

\section{Éditeur}

Presses universitaires de Caen

\section{Édition imprimée}

Date de publication : 30 octobre 2012

Pagination : 177-178

ISBN : 978-7535-2158-2

ISSN : 0183-973X

\section{Référence électronique}

Christophe Gillissen, «Ireland at the United Nations: Memories of the Early Years A Small State at the Top Table: Memories of Ireland at the Security Council, 1981-82 ", Études irlandaises [En ligne], 37-2 I 2012, mis en ligne le 30 octobre 2012, consulté le 04 août 2022. URL : http://journals.openedition.org/ etudesirlandaises/3238; DOI : https://doi.org/10.4000/etudesirlandaises.3238

Ce document a été généré automatiquement le 4 août 2022.

\section{c) (†)}

Creative Commons - Attribution - Pas d'Utilisation Commerciale - Partage dans les Mêmes Conditions 4.0 International - CC BY-NC-SA 4.0

https://creativecommons.org/licenses/by-nc-sa/4.0/ 


\title{
Ireland at the United Nations:
} Memories of the Early Years A Small State at the Top Table: Memories of Ireland at the Security Council,

\section{1-82}

\author{
Christophe Gillissen
}

\section{RÉFÉRENCE}

Noel DORR, Ireland at the United Nations: Memories of the Early Years, Dublin, Institute of Public Administration, 2010. 242 p., ISBN 978190454187 5, $25 €$.

A Small State at the Top Table: Memories of Ireland at the Security Council, 1981-1982, Dublin, Institute of Public Administration, 2011, 264 p., ISBN 978190454196 7, $25 €$.

1 Diplomate à la retraite, Noel Dorr connaît fort bien les rouages de l'ONU où il a longtemps représenté l'Irlande. En 2003, peu avant la guerre d'Irak, lorsqu'il fut amené à expliquer les enjeux des votes et résolutions dans les médias, il s'aperçut que l'opinion publique de son pays n'avait qu'une compréhension limitée de l'organisation. Aussi décida-t-il d'en rédiger une histoire destinée à un large public. Elle tient en deux volumes, qui relèvent en partie de mémoires, puisque l'auteur s'appuie sur son expérience personnelle et livre nombre d'anecdotes révélatrices.

2 Après avoir présenté les origines et le fonctionnement de l'ONU, le premier volume se penche sur le rôle de l'Irlande depuis son admission dans l'organisation en 1955 jusqu'à la fin des années soixante. Il couvre nombre de questions, comme l'envoi de Casques bleus au Congo en 1960 - où les soldats irlandais payèrent un lourd tribut -, la discussion du conflit en Irlande du Nord au Conseil de sécurité en 1969, ou encore le Traité de non-prolifération des armes nucléaires et la décolonisation, deux dossiers où l'Irlande se distingua. 
3 Si plusieurs publications ont déjà apporté des éclairages sur ces questions, Dorr livre le témoignage d'un homme au cour des événements et en contact avec les principaux acteurs. Ses mémoires sont d'autant plus appréciables qu'il cherche à relater les choses de manière équitable, notamment pour ce qui est de la personnalité de ses collègues. Jusqu'à présent, cette dimension humaine était restée marquée par l'œuvre de Conor Cruise o'Brien, dont la plume talentueuse n'était pas toujours tendre à l'égard de ceux avec qui il lui arrivait d'être en désaccord. Désormais nous avons une perception plus nuancée de personnes comme Frank Aiken, ministre des Affaires extérieures de 1957 à 1969.

4 Le second volume traite des années 1981-1982, lorsque l'Irlande occupa un siège non-permanent au Conseil de sécurité et dut prendre position sur l'indépendance de la Namibie, la première guerre du Liban, et la guerre des Malouines, trois enjeux que l'auteur a choisi de développer. Le troisième, le plus sensible, occupe la place centrale. En effet, le 4 mai 1982, après le torpillage du Belgrano par un sous-marin britannique, une déclaration de Dublin fit sensation : elle demandait une réunion immédiate du Conseil de sécurité, pour appeler une fin immédiate aux hostilités et la négociation d'un accord diplomatique sous l'égide de l'ONU. Cette initiative, imposée par le Premier ministre, Charles Haughey, contre les recommandations du ministère, créa des tensions considérables entre Dublin et Londres et mit Dorr dans une position difficile. Négociations tortueuses en coulisses, textes remaniés sans fin, tout cela est relaté en détail, offrant ainsi au lecteur un aperçu du quotidien des diplomates à New York.

5 Il s'agit en somme d'une source de première main d'un grand intérêt pour quiconque s'intéresse à la politique menée par l'Irlande dans le cadre de l'ONU. Grâce à ces mémoires, on comprend mieux la réputation flatteuse de la délégation irlandaise à New York.

\section{AUTEURS}

\section{CHRISTOPHE GILLISSEN}

Université Paris-Sorbonne 